\title{
Research on Urban Network of Wuhan Metropolitan Area in China Based on Social Network Analysis
}

\author{
Jing-Xin Nie, Ya-Ping Huang, and Pei Chen
}

\begin{abstract}
This article is based on the retrospect of theoretical way and analysis method of town correlation measure, summarized the advantages and disadvantages. Then the article proposed the social network analysis method with network data of express, in order to analyze the town correlation measure. Taking Wuhan metropolitan area in china as practical experiment objects, and found out the network characteristics of it, which dominance and polarization coexisted, axes and corridors gathered in space. In the view of social network, the urban system of Wuhan metropolitan area has not been completed, though the inner core group has formed, but the connection between the low-level nodes is not strong enough.
\end{abstract}

Index Terms-Express network, social network analysis, Wuhan metropolitan area, urban network.

\section{INTRODUCTION}

In recent years, it becomes a new direction in the research of urban geography [1], which information technology influences on the regional network. There has been a certain amount of research of urban system based on net information space all over the world. High technology, space, and society, written by Manuel Castells in 1985, put forward the concept of flowing space for the first time. At present, urban network researches based on flowing space mainly adopt two methods, infrastructure method and enterprise organization method. Infrastructure method analyzes urban network formed by infrastructure based on human, goods and information flow. Such as research on urban network represented by air transport network by Derudder etc. [2]-[4], research on urban network based on Internet infrastructure by Abramson etc. [5]-[8], research on urban network in China based on traffic and information infrastructure by Feng-jun Jin etc. [9]-[14]. Enterprise organization method sets the organizations as representatives of city, study their operation in the process of creating city relationships, so as to analyze the urban network pattern [15]-[19]. One of the most typical researches is a category represented by the GaWC team, which study about the distribution of the worldwide producer service company headquarters and branches. Additionally, there was a research on intercity relational network of politics and culture based on data analysis of intercity political organization and social organization by Taylor etc. [20], [21]. In China, Jun Yin and Feng Zhen etc. studied on urban network empirical research

Manuscript received October 14, 2016; revised March 1, 2017. This work was supported in part by the National Natural Science Foundation of China under fund 51478199, 51538004

The authors are with the School of Architecture and Urban Planning, Huazhong University of Science and Technology, Wuhan, Hubei, China, PC 430074 China (e-mail: 15207158960@163.com, hust_hyp@sina.com, chenpei@ hust.edu.cn). according to enterprise organizations [22], [23].

The essence of urban network is intercity relation, and relational data is always applied in urban network research. With the rapid development of information and communication technology, distance of space and time between cities is greatly compressed, and the connections between cities are more and more closely. Excavating relational data has become a new trend in research of urban network. Social Network Analysis, SNA for short, is a methodology which describes the whole form, characteristics and structure of network. SNA has obvious advantage in relation expression; a network can be regarded either as a whole or a part, so that reveals the integration and hierarchy of a network, and explains the compactness of connection in a network and the different relationship among network nodes, then finds out the network connection and the decomposition model. The spatial organization of express companies reflects the need of social service of citizen. And it is certain that, flow and direction of express maintain consistency with the attraction of the city and the relationship among cities. Therefore, express data can be used as data resources in urban network researches. This article tried to integrate the urban network character of Wuhan metropolitan area, in perspectives of general characteristics, centricity, core-periphery structure and cohesive subgroups, using the method of SNA and analyzing Software Ucinet.

\section{RESEARCH METHODS}

\section{A. Research Unit Division}

Wuhan metropolitan area, which core city is Wuhan, with a radius of $100 \mathrm{~km}$ of urban agglomeration, including Huangshi, Ezhou, Huanggang, Xiaogan, Xianning, Xiantao, Qianjiang, Tianmen, and three observer cities (Honghu, Jingshan and Guangshui), 12 cities in total. And the research divided the area into 33 units.

\section{B. Data Processing}

According to open data site, Express 100 (The URL is http://www.kuaidi100.com/, up to December 2015.) and Express Check (The URL is http://www.ickd.cn/, up to December 2015. ) , we have got the original spatial distribution situation of express sites in Wuhan metropolitan area. After de-noise processing, we made out the spatial distribution situation of 26 express companies. Firstly, we measure the intercity relevancy of every one certain express company. Secondly, it came out a weighted index based on the proportion of each express company, and then we constructed an association degree matrix of districts, towns 
and cities. Finally, put the association degree matrix into SNA software for further analyze. The approach of modeling the association degree matrix is as below.

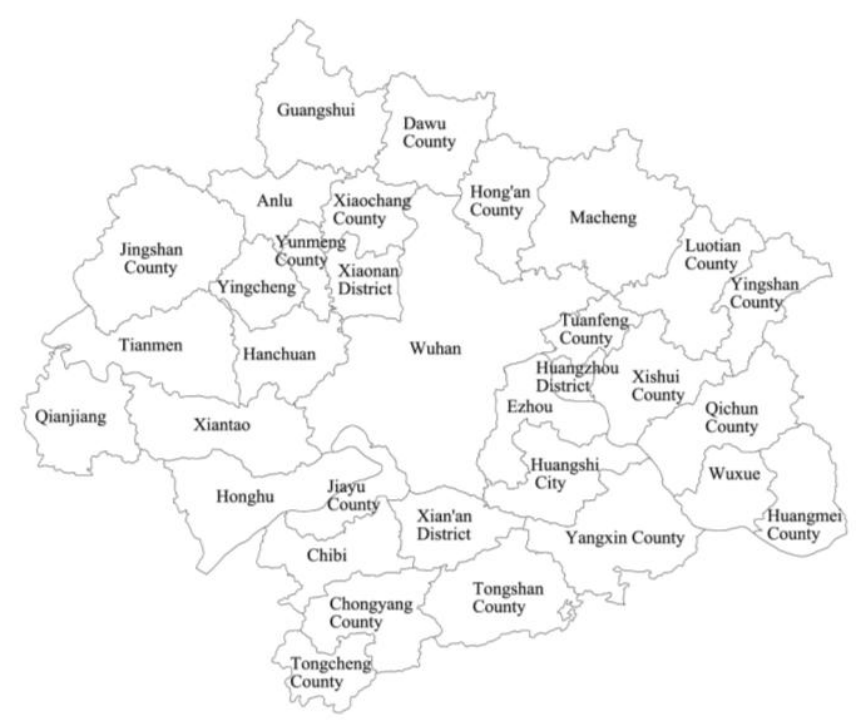

Fig. 1. The division of regional scope and analysis units.

Step one, model the association degree matrix of express sites number of every express company. The sum of express sites map of every two spatial units represents the relevancy of them. The formula is as in (1).

$$
\begin{aligned}
& N_{i j}=N_{i} \times N_{j} \\
& T^{\mathrm{k}}=\left\{N_{i j}\right\}
\end{aligned}
$$

In the formula, $N_{i}$ is the express sites number in unit I; $N_{j}$ is the express sites number of the same company in unit $\mathrm{j} ; \mathrm{N}_{\mathrm{ij}}$ is the relevancy of unit $i$ and $j ; T^{k}$ is the association degree matrix in the whole area of one company.

Step two; make a weighted summation of the association degree matrix of every express company. And then it can come out the association degree matrix of districts, towns and cities. The formula is as in (2).

$$
\begin{aligned}
& R=\left(T^{1} \times \frac{M_{1}}{\sum M_{k}}\right)+\left(T^{2} \times \frac{M_{2}}{\sum M_{k}}\right)+\ldots+\left(T^{k} \times \frac{M_{k}}{\sum M_{k}}\right) \\
& R^{\prime}=R / \operatorname{Max}\left(R_{i j}\right)
\end{aligned}
$$

In the formula, $R$ is the original matrix of a weighted summation of the association degree matrix of every express company; MK is the total number of express sites of company $k ; R^{\prime}$ is the association degree matrix of districts, towns and cities after data standardization; $\operatorname{Max}\left(R_{i j}\right)$ is the maximum of matrix $R$ after wiping out the diagonal line.

\section{URBAN NETWORK CHARACTERISTICS}

\section{A. Overall Network Characteristics}

Applying the software Ucinet for density analysis, and result shows that, the overall density of urban network of Wuhan metropolitan area is 1.7403 , and the relevance standard deviation is 7.5062. These data show that, the relevance network among cities and towns is still relatively intensive, but the degrees are quite different. A total of 528 pairs of correlations are divided into 6 levels using natural break points, of which the first 4 levels represent the external relations of Wuhan, and the fifth level represents the external relations of city center of Wuhan, Ezhou and Huangshi City. It reflects the high concentration of urban network association intensity in the three core cities. On the whole, Wuhan metropolitan area presents "single center" network structure. Wuhan plays a vital role in the network architecture, the top $5 \%$ of the relevance degrees are the external relations of Wuhan, and that among the other cities are small. The relevance degrees present a pyramid increase, the number of low-grade cities and towns is high, and the external correlation is low. The level of polarization reflects the non-equilibrium characteristics of the network.

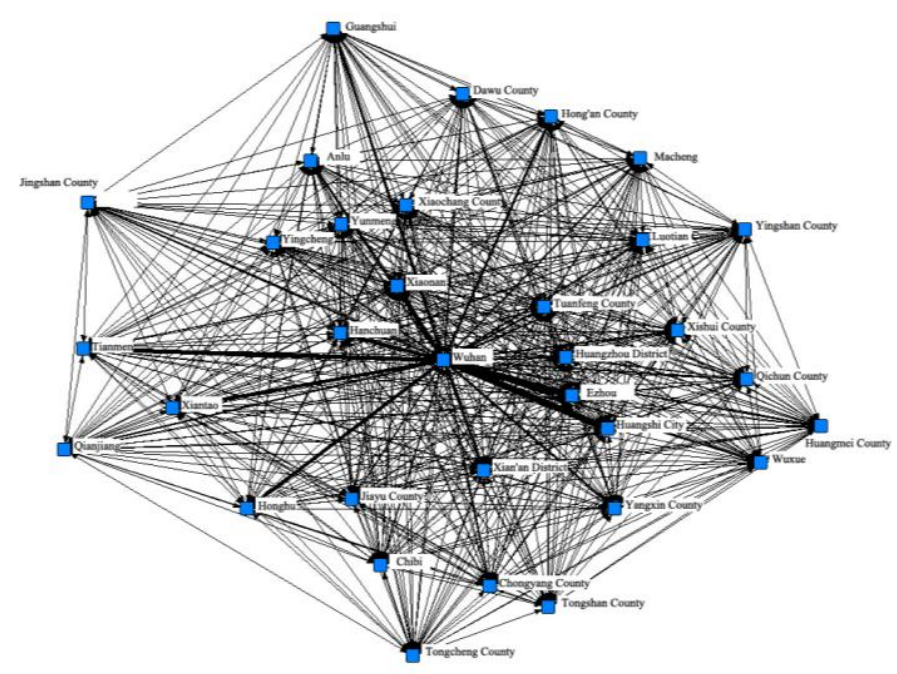

Fig. 2. Town - related network of Wuhan metropolitan area.

\section{B. Centrality Analysis}

Centrality, the central power index and other indicators are used for quantitative analysis of power in social network from the perspective of the "relationship". We can get the urban network hierarchy by measuring the status of different urban counties and towns in the network, through the quantitative analysis of the centrality. Wuhan metropolitan area network's calculated center potential is $73.39 \%$, intermediate index is $27.17 \%$, which indicates that the importance of the center of the nodes in the network --Wuhan, its highest node certain degree is enough to control the entire network, and it undertakes extremely important bridge in the express network, occupies the key position of resources and information circulation. After the standardization, the value of degree centrality ranges from 32 to 1 , the value of betweenness centrality ranges from 0 to 141.695 for all the 33 units in the network as in table1. The highest nodes of two types of centrality are all Wuhan. Nodes which account the proportion more than $5 \%$ of the degree and betweenness centrality value are Wuhan, Huangshi City, Ezhou, Tianmen, Xiaonan District, Honghu and Xiantao. Compared with the degree centrality, the urban network's intermediary function is more concentrated in the top seven of these urban nodes. The relative difference between degree centrality is smaller, the 
top three nodes: Wuhan, Huangshi City, Ezhou almost have the same value. The relative difference begins to increase from seventh node Xiantao, with a larger gap between towns ahead in degree centrality. The betweenness centrality value of the relative difference is more than the degree centrality value. The betweenness centrality value of primate city Wuhan is 1.76 times as much as second city --Huangshi City, and 2.12 times for the third city Ezhou. The valued betweenness centrality of city nodes in the network is only the first eight cities, which accounts for less than 1/4 of the total. The imbalance of the betweenness centrality level distribution is more significant.

Wuhan takes the absolute center position in the network; "Wuhan-Huangshi City-Ezhou-Xiaonan District-Tianmen" is an important node group in the network, as in fig.3and 4. City nodes with a low centrality value are in a radial shape and are on the edge of the network. The dielectric distribution network basic pattern of two types of centrality is similar, which is circle structure. The group "Wuhan - Ezhou Huangshi City" has a prominent core position, and links the whole network.

\section{TABLE I: The Central Value of Each Unit}

\begin{tabular}{|c|c|c|c|c|c|}
\hline unit & $\begin{array}{l}\text { degree } \\
\text { trality }\end{array}$ & $\begin{array}{l}\text { betweenness } \\
\text { centrality }\end{array}$ & unit & $\begin{array}{l}\text { degree } \\
\text { centrality }\end{array}$ & $\begin{array}{l}\text { betweenness } \\
\text { centrality } \\
\end{array}$ \\
\hline Wuhan & 32 & 141.695 & Macheng & 7 & 0 \\
\hline $\begin{array}{l}\text { Huangshi } \\
\text { City }\end{array}$ & 30 & 80.695 & $\begin{array}{l}\text { Huangmei } \\
\text { County }\end{array}$ & 7 & 0 \\
\hline Ezhou & 29 & 66.695 & $\begin{array}{l}\text { Huangzhou } \\
\text { District }\end{array}$ & 6 & 0 \\
\hline Tianmen & 25 & 34.029 & $\begin{array}{l}\text { Chongyang } \\
\text { County }\end{array}$ & 6 & 0 \\
\hline $\begin{array}{l}\text { Xiaonan } \\
\text { District }\end{array}$ & 22 & 19.029 & Wuxue & 5 & 0 \\
\hline Honghu & 20 & 12.429 & Yingcheng & 5 & 0 \\
\hline Xiantao & 18 & 7.929 & $\begin{array}{l}\text { Qichun } \\
\text { County }\end{array}$ & 4 & 0 \\
\hline Hanchuan & 13 & 1.5 & $\begin{array}{l}\text { Luotian } \\
\text { County }\end{array}$ & 4 & 0 \\
\hline $\begin{array}{l}\text { Yangxin } \\
\text { County }\end{array}$ & 10 & 0 & $\begin{array}{l}\text { Tuanfeng } \\
\text { County }\end{array}$ & 4 & 0 \\
\hline Guangshui & 10 & 0 & $\begin{array}{l}\text { Yingshan } \\
\text { County }\end{array}$ & 3 & 0 \\
\hline $\begin{array}{l}\text { Xian'an } \\
\text { District }\end{array}$ & 10 & 0 & $\begin{array}{l}\text { Yunmeng } \\
\text { County }\end{array}$ & 3 & 0 \\
\hline Anlu & 8 & 0 & $\begin{array}{l}\text { Dawu } \\
\text { County }\end{array}$ & 3 & 0 \\
\hline Qianjiang & 8 & 0 & Chibi & 3 & 0 \\
\hline $\begin{array}{l}\text { Hong'an } \\
\text { County }\end{array}$ & 8 & 0 & $\begin{array}{l}\text { Tongshan } \\
\text { County }\end{array}$ & 2 & 0 \\
\hline $\begin{array}{l}\text { Jiayu } \\
\text { County }\end{array}$ & 7 & 0 & $\begin{array}{l}\text { Tongcheng } \\
\text { County }\end{array}$ & 1 & 0 \\
\hline $\begin{array}{l}\text { Jingshan } \\
\text { County }\end{array}$ & 7 & 0 & $\begin{array}{l}\text { Xiaochang } \\
\text { County }\end{array}$ & 1 & 0 \\
\hline $\begin{array}{l}\text { Xishui } \\
\text { County }\end{array}$ & 7 & 0 & -- & -- & -- \\
\hline
\end{tabular}

\section{Core-Periphery Analysis}

Research on the core-periphery structure, we can not only judge whether the whole network has the core-periphery structure, and find out the key nodes in the network, but also can quantify the driving effect of the core to the periphery. Using the core-periphery deletion model, the correlation coefficient of the real data and the ideal matrix is 0.998 .Then, using the core-periphery continuous model to get the coreness of all nodes, finding that the correlation coefficient was 1.000 . According to the coreness to rearrangement the original network matrix, further subdividing core, semi periphery and periphery of the node-city in the network. Among them, the top3 core nodes of the network are consistent with the centrality analysis, and their total coreness value of the network is $75.2 \%$ as in Table II. There are 8 semi periphery cities in the network, and the other 22 periphery cities as in Fig. 5. It is thus evident that, the number distribution of the core nodes on the basis of the express network is similar to the physical space, also showing a "Pyramid" structure. In addition to the top3 cities in the network center, the semi periphery cities also tend to gather in the network, which is consistent with the distribution of the centrality. But the disparity of coreness value in both the network core area and the periphery area has a big gap, showing a typical "core semi periphery - periphery" Three - level distribution Pattern.

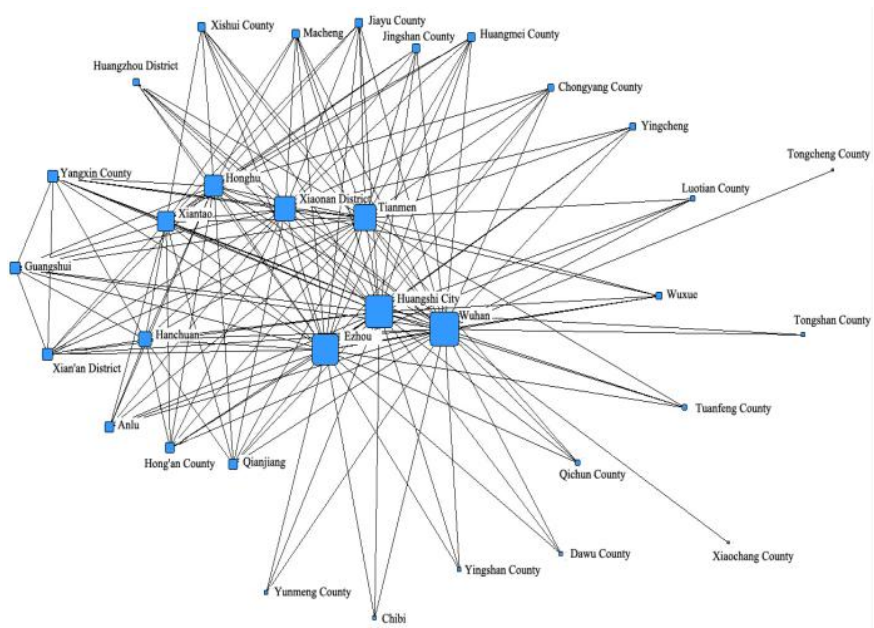

Fig. 3. Degree centrality network analysis.

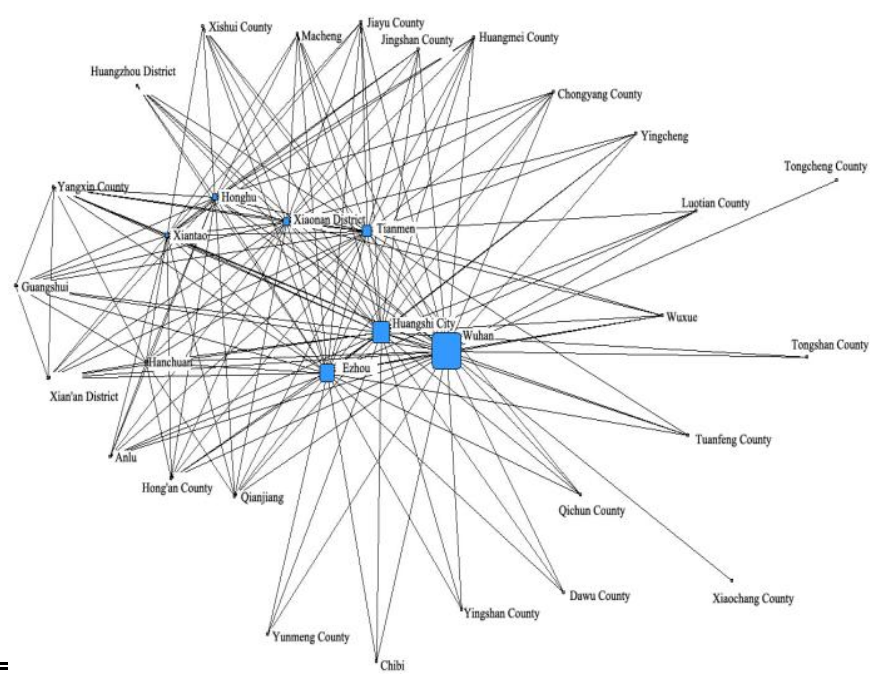

Fig. 4. Betweenness centrality network analysis.

\section{Cohesive Subgroup Analysis}

When some of the actors in the network are so closely 
related that they are combined into a sub group, such groups are called agglomeration subgroups in social network analysis. Using K-plex algorithm, when the size Minimum and $\mathrm{K}$ values were 6 and 1, the urban network clustering based on the information space as shown in Fig. 6. The urban network structure of the Wuhan Metropolitan Area which based on the express network has lowly broken degree, but the correlation level is not high. Urban subgroup with high connectivity in the network is less. When the strength of network connectivity more than 10 , there is only Wuhan as single center radiating outward other 25 space units as in Fig. 7. "Wuhan - Huangshi City - Ezhou city - Xiaonan District - Tianmen "four city making up a powerful group when information connectivity level over 13. This is the core of the urban system of the Wuhan Metropolitan Area at the same time.

TABLE II: RANK OF THE CORENESS DEGREE OF EACH UNIT

\begin{tabular}{llll}
\hline \hline unit & $\begin{array}{l}\text { coreness } \\
\text { degree }\end{array}$ & unit & $\begin{array}{l}\text { coreness } \\
\text { degree }\end{array}$ \\
\hline Wuhan & 0.993 & Qianjiang & 0.011 \\
Huangshi City & 0.066 & Huangmei County & 0.01 \\
Ezhou & 0.055 & Chongyang County & 0.01 \\
Xiaonan District & 0.032 & Wuxue & 0.009 \\
Tianmen & 0.03 & Yingcheng & 0.009 \\
Honghu & 0.026 & Jingshan County & 0.009 \\
Hanchuan & 0.022 & Tuanfeng County & 0.008 \\
Xiantao & 0.022 & Yingshan County & 0.007 \\
Yangxin County & 0.017 & Luotian County & 0.007 \\
Xian'an District & 0.017 & Qichun County & 0.007 \\
Guangshui & 0.016 & Chibi & 0.006 \\
Hong'an County & 0.013 & Yunmeng County & 0.005 \\
Anlu & 0.013 & Dawu County & 0.005 \\
Huangzhou District & 0.012 & Tongshan County & 0.004 \\
Xishui County & 0.012 & Tongcheng County & 0.003 \\
Jiayu County & 0.012 & Xiaochang County & 0.002 \\
Macheng & 0.011 & -- & -- \\
\hline \hline
\end{tabular}

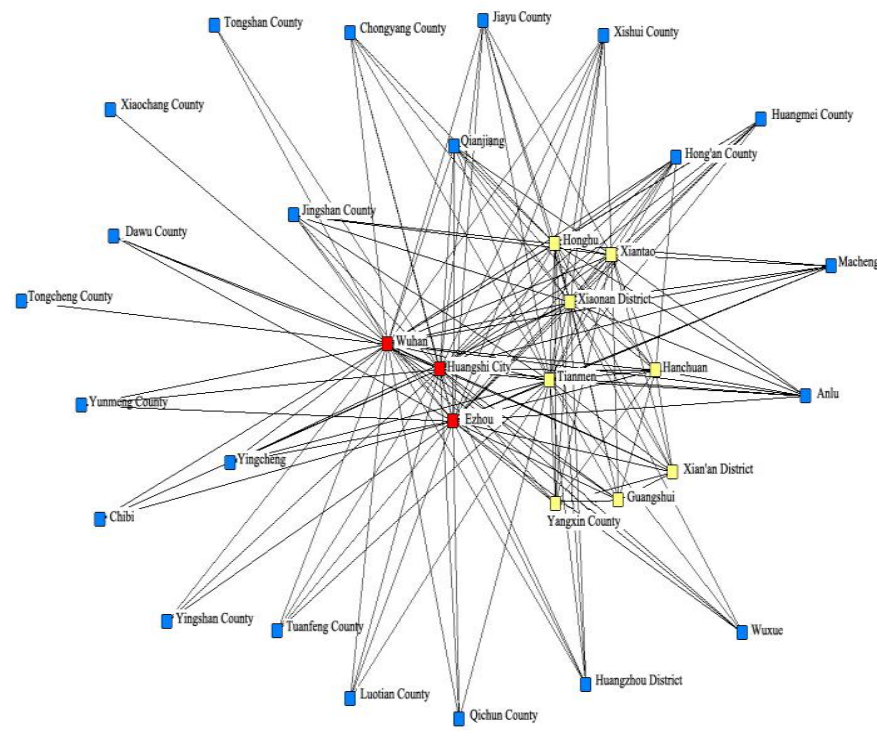

Fig. 5. Core-periphery city network structure.

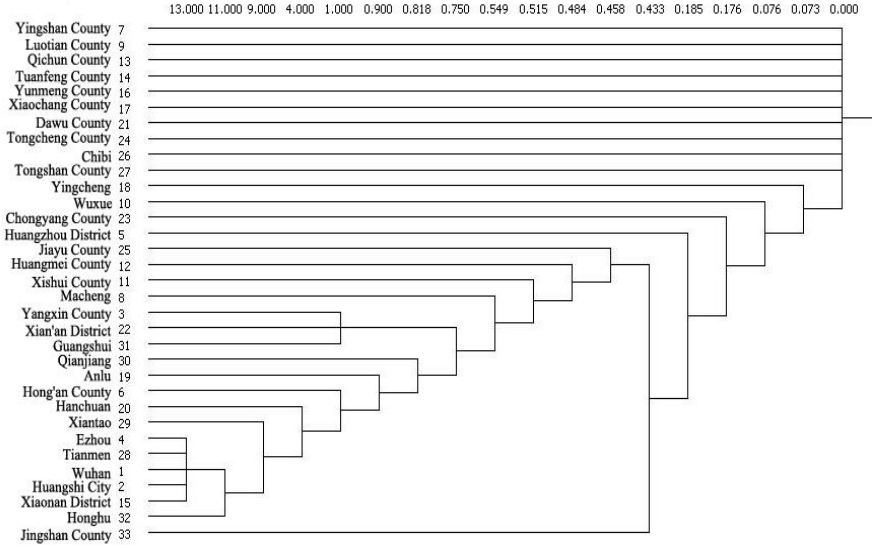

Fig. 6. K-plex cluster analysis of express network.

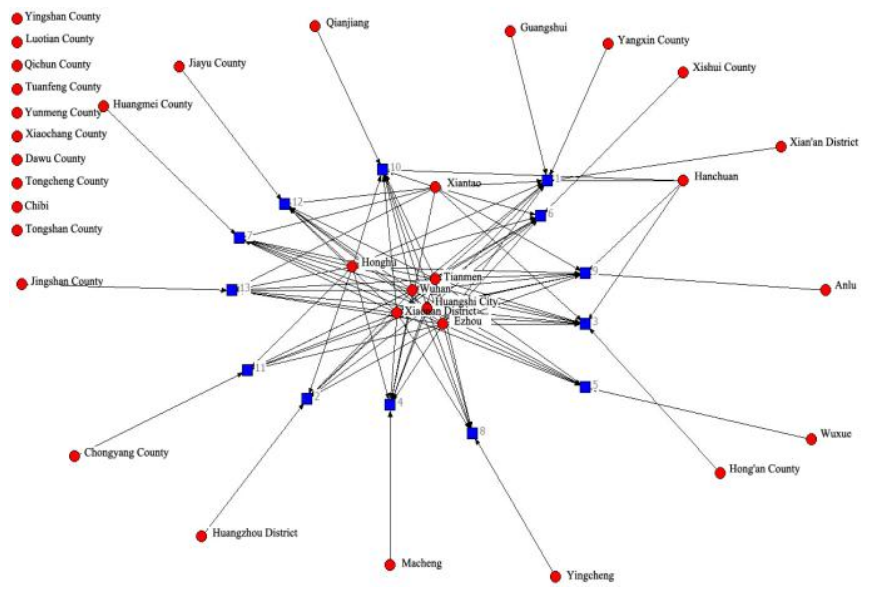

Fig. 7. K-core subgroup of express network.

\section{CONCLUSION}

We can see that the Wuhan Metropolitan Area has an obviously single-center structure, by constructing the urban network through the express outlets data. Each unit has formed a certain link network. As the central city of the whole area, Wuhan plays a key role in the distribution of resources and information flow, and guides the development of the region. It is the bridge between the metropolitan area and the external world, playing with a decisive portal role. "Wuhan -Ezhou- Huangshi City" is the core city-group. "Wuhan Huangshi City - Ezhou - Xiaonan district - Tianmen" is composed of a main group of the metropolitan area which forming an east - west intensive urban clusters in the space, so that the metropolitan area is clearly divided into the core circle and the peripheral circle. On the other hand, the number of subgroups within the network is not considerable. Insufficiently internal cooperation may restrict the further development of this area. With the intensification of global competition, setting up a harmonious urban network becomes necessary, also should get more social attention. At the same time, we can realize that the urban network is very complex, the data used in this study is single, multi-source data, a variety of methods should be used to further study.

\section{REFERENCES}

[1] F. Zhen, X. X. Liu, and H. Liu, "Regional urban network influenced by information technology: New directions of urban studies," Human Geography, vol. 22, no. 2, pp. 76-80, Apr. 2007. 
[2] B. Derudder and F. Witlox, "An appraisal of the use of airline data in assessing the world city network: A research note on data," Urban Studies, vol. 42, no. 13, pp. 2371- 2388, Dec. 2005.

[3] M. C. Burns, J. R. Cladera, and M. M. Bergad, "The spatial implications of the functional proximity deriving from air passenger flows between European metropolitan urban regions," GeoJournal, vol. 72, no. 1, pp. 37- 52, Apr. 2008.

[4] B. Derudder, F. Witlox, J. Faulconbridge, and J. V. Beaverstock, "Airline data for global city network research: reviewing and refining existing approaches," GeoJournal, vol. 71, no. 1, pp. 5-18, Jan. 2008.

[5] B. D. Abramson, "Internet globalization indicators," Telecommunications Policy, vol. 24, no. 1, pp. 69-74, 2000.

[6] H. Rood, "Indicators for band width demand," Telecommunications Policy, vol. 24, no. 3, pp. 263-270, 2000.

[7] A. M. Townsend, "Network cities and the global structure of the internet," American Behavioral Scientist, vol. 44, no. 10, pp. 1697-1716, Jun. 2001

[8] S. D. Brunn and M. Dodge, "Mapping the worlds of the world wide web," American Behavioral Scientist, vol. 44, no. 10, pp. 1717-1739, Jun. 2001.

[9] F. J. Jin and C. J. Wang, "Hub-and-spoke system and China aviation network organization," Geographical Research, vol. 24, no. 5, pp. 774-784, Oct. 2005.

[10] F. J. Jin and J. Wang, "Railway network expansion and spatial accessibility analysis in China: 1906 2000," Acta Geographica Sinica vol. 59, no. 2, pp. 293-302, Sep. 2004.

[11] W. Wu, Y. H. Cao, S. B. Liang, and W. D. Cao, "The accessibility pattern of railway passenger transport network in China," Geographical Research, vol. 28, no. 5, pp. 1389-1400, Sep. 2009

[12] M. F. Wang and Y. M. Ning, "The network advantage of cities: An analysis of spatial structure and node accessibility of Internet backbones in China," Geographical Research, vol. 25, no. 2, pp. 193-203, Mar. 2006.

[13] Z. L. Tang and M. X. Zhao, "Economic globalization and transformation of urban system in the Yangtze river delta region: Interlocking network and value-added hierarchy," Urban Planning Forum, no. 1, pp. 38-45, Jan. 2010.

[14] T. Q. Dai, F. J. Jin, and J. Wang, "Spatial interaction and network structure evolvement of cities in term of china's railway passenger flow in 1990s," Progress in Geography, vol. 24, no. 2, pp. 80-89, Mar. 2005.

[15] S. S. Fainstein and S. Campbell, Readings in Urban Theory, Oxford, U.K.: Blackwell Publishers, 2002, pp. 32-56.

[16] P. J. Taylor, World City Network: A Global Urban Analysis, London, U.K.: Routledge, 2004.

[17] D. Doloreux, M. Freel and R. Shearmur, Knowledge-intensive Business Services: Geography and Innovation, Alderhsot: Ashgate, 2010.
[18] J. Wouter, K. Hans, and H. Peter. "The location and global network structure of maritime advanced producer services," Urban Studies, vol. 48, no. 13, pp. 2749-2769, Oct. 2011.

[19] E. C. Rossi, J. V. Beaverstock, and P. J. Taylor, "Transaction links through cities: 'Decision cities' and service cities in outsourcing by leading Brazilian firms," Geoforum, vol. 38, no. 4, pp. 628-642, Jul. 2007.

[20] P. J. Taylor, "The new geography of global civil society: NGOs in the world city network," Globalizations, vol. 1, no. 2, pp. 265-277, Dec. 2004.

[21] P. J. Taylor, "New political geographies: Global civil society and global governance through world city networks," Political Geography, vol. 24, no. 6, pp. 703-730, Aug. 2005.

[22] J. Yin, F. Zhen, and C. H. Wang, "China's city network pattern: An empirical analysis based on financial enterprises layout," Economic Geography, vol. 31, no. 5, pp. 754-759, May 2011.

[23] F. Zhen, X. Wang, J. Yin, and M. Zhang, "An empirical study on Chinese city network pattern based on producer services," Chinese Geographical Science, vol. 23, no. 3, pp. 274-285, Jun. 2013.

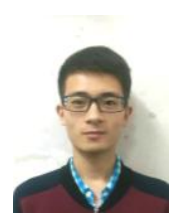

Jing-xin Nie was born in 1991, at Hubei province, China He got a bachelor of engineering in urban planning in 2015. He is pursuing for further study as a test-free postgraduate student in School of Architecture and Urban Planning, Huazhong University of Science and Technology since Sep. 2015. His research field is regional planning and development.

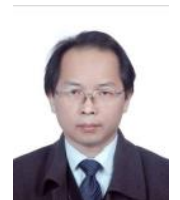

Ya-ping Huang was born in 1964, at Hubei province, China. He is a professor, a doctoral supervisor, a dean of School of Architecture and Urban Planning. The National Registered Planner, the member of Academic Committee on Urban Planning Society of China (UPSC), and Academic Committee on Urban and Rural Planning in Mountainous Region of Urban Planning Society of China. The member of National Education Steering Committee on Urban Planning Major of Colleges and Universities, Chairman of Urban and Rural Planning Society of Hubei Province. The magazine editor of Urban Planning Forum, etc. Published 6 works, 3 symposiums and portfolios as the chief editor, and over 70 theses.

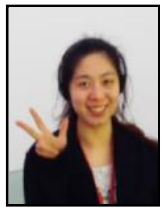

Pei Chen was born in 1989, at Hubei province, China. She got a bachelor of engineering in urban planning and a bachelor of arts in English in 2013. She is pursuing for further study as a doctoral student in Faculty of Architecture and Urban Planning, Huazhong University of Science and Technology, since Sep. 2015. Her research field is regional planning and development. 